\title{
Anemia, diet and therapeutic iron among children living with HIV: a prospective cohort study
}

Anita Shet ${ }^{1,2^{*}}$, PK Bhavani ${ }^{3}$, N. Kumarasamy ${ }^{4}$, Karthika Arumugam ${ }^{1}$ S. Poongulali ${ }^{4}$, Suresh Elumalai ${ }^{5}$ and Soumya Swaminathan ${ }^{6}$

\begin{abstract}
Background: Children living with HIV have higher-than-normal prevalence of anemia. The beneficial effect of therapeutic iron has been questioned in the setting of high prevalence of infections. This study examines anemia prevalence and effect of standard therapeutic iron on HIV disease progression among children.

Methods: Perinatally-infected children aged 2-12 years were enrolled at three sites in southern India, and were followed for 1 year with clinical assessments, dietary recall and anthropometry. Laboratory parameters included iron markers (ferritin, soluble transferrin receptor) and other micronutrient levels (vitamin $A, B_{12}$, folate). Iron was given to anemic children based on WHO guidelines. Statistical analyses including frequency distributions, chi square tests and multivariate logistic regression were performed using Stata v13.0.

Results: Among 240 children enrolled (mean age 7.7 years, $54.6 \%$ males), median CD4 was $25 \%, 19.2 \%$ had advanced disease, $45.5 \%$ had malnutrition, and $43.3 \%$ were on antiretroviral treatment (ART) at baseline. Anemia was prevalent in $47.1 \%(113 / 240)$ children. Iron deficiency was present in $65.5 \%$; vitamin A and vitamin $B_{12}$ deficiency in $26.6 \%$ and $8.0 \%$ respectively; and anemia of inflammation in $58.4 \%$. Independent risk factors for anemia were stunting, CD4 $<25 \%$, detectable viral load $\geq 400$ copies/ml and vitamin A deficiency. Inadequate dietary iron was prominent; $77.9 \%$ obtained less than two-thirds of recommended daily iron. Among clinically anemic children who took iron, overall adherence to iron therapy was good, and only minor self-limiting adverse events were reported. Median hemoglobin rose from $10.4 \mathrm{~g} / \mathrm{dl}$ to $10.9 \mathrm{mg} / \mathrm{dl}$ among those who took iron for 3 months, and peaked at $11.3 \mathrm{mg} / \mathrm{dl}$ with iron taken for up to 6 months. Iron was also associated with a greater fall in clinical severity of HIV stage; however when adjusted for use of ART, was not associated with improvement in growth, inflammatory and CD4 parameters.
\end{abstract}

Conclusions: Children living with HIV in India have a high prevalence of anemia mediated by iron deficiency, vitamin A deficiency and chronic inflammation. The use of therapeutic iron for durations up to 6 months appears to be safe in this setting, and is associated with beneficial effects on anemia, iron deficiency and HIV disease progression.

Keywords: HIV, Anemia, Children, Iron deficiency, Anemia of chronic disease, Dietary iron, Iron therapy, India

\footnotetext{
* Correspondence: anitashet@gmail.com

'Department of Pediatrics, St. John's Medical College Hospital, Sarjapur Road,

Bangalore 560034, India

${ }^{2}$ Department of Public Health Sciences, Karolinska Institutet, Stockholm,

Sweden

Full list of author information is available at the end of the article
}

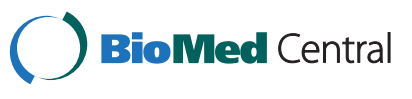

(c) 2015 Shet et al. Open Access This article is distributed under the terms of the Creative Commons Attribution 4.0 International License (http://creativecommons.org/licenses/by/4.0/), which permits unrestricted use, distribution, and reproduction in any medium, provided you give appropriate credit to the original author(s) and the source, provide a link to the Creative Commons license, and indicate if changes were made. The Creative Commons Public Domain Dedication waiver (http://creativecommons.org/publicdomain/zero/1.0/) applies to the data made available in this article, unless otherwise stated. 


\section{Background}

Anemia is a common co-morbid condition among HIVinfected children and has a profound impact on disease progression and mortality [1-4]. A review of this topic indicated that anemia prevalence is higher among HIVinfected children compared to HIV-uninfected children in both high and low-income settings [5]. Since anemia and malnutrition are reported in over $50 \%$ of HIVinfected children in low-income settings [6-9], it is important to understand further the etiology and risk factors for development of anemia. The practice of giving iron to HIV-infected children is based on weak evidence, particularly in areas with high prevalence of HIV, anemia and malaria [10]. Routine use of iron in malaria-endemic settings has been shown to have detrimental effects, particularly among those children who are not iron deficient [11]. Understanding the role of iron therapy in anemia has important implications for the clinical evaluation and treatment of HIV-infected children, as well as for designing national policies on nutritional interventions in these children.

To explore anemia among children living with HIV and the role of iron therapy, we conducted a multicentric study to examine the prevalence and risk factors of anemia and related micronutrient deficiencies such as iron, folic acid, vitamin $\mathrm{B}_{12}$ and vitamin $\mathrm{A}$, among a cohort of children with perinatally-acquired HIV infection in southern India. We hypothesized that, in addition to nutritional factors including dietary intake, non-nutritional factors such as anemia of chronic inflammation play an important etiological role in childhood anemia in the context of HIV infection. We also examined the effect of anemia and therapeutic iron on growth, HIV disease progression and micronutrient deficiency status.

\section{Methods}

\section{Study population}

Children with perinatally acquired HIV infection aged between 2 and 12 years were screened and enrolled at three sites in South India, St John's Hospital, Bangalore (a public-private partnership HIV center), National Institute for Research in Tuberculosis, Chennai (a public-funded research institute) and YRG Centre for AIDS Research and Education, Chennai (a private non-profit institution providing HIV care). Perinatally acquired HIV infection in children was indicated by history or documentation of one or both parents being HIV-infected. Both antiretroviral therapy (ART)-naïve (no perinatal or prior ART exposure) and ART-experienced children (on ART for at least 6 months) were included. Children younger than 2 years and older than 12 years were not included as they were likely to have varying nutrient requirements due to growth and pubertal changes. Children who had received any blood component transfusion within the past 6 weeks were excluded from the study.

\section{Ethical considerations}

Written informed consent was obtained from the parent or legal guardian prior to enrolment. In addition, assent was obtained from children 8 years and older. The institutional review boards at all three participating sites approved the study.

\section{Study procedures}

At the baseline visit, information on clinical history, socio-demographic details, current antiretroviral therapy, nutritional supplements and other medications was obtained. A complete physical examination was done, and HIV diagnosis documentation was verified. Anthropometric measurements included weight, height and midarm circumference. For younger children (aged between 2 and 4 years) recumbent length, instead of height was measured to the nearest $0.1 \mathrm{~cm}$ using a length of wooden board with a sliding foot piece. Height-for-age Z-scores, weight-for-age Z-scores and weight-for-height Z-scores were calculated (EpiInfo 3.3.2) based on the World Health Organization (WHO) Growth Standards of 2007 [12].

A 24-hour dietary recall was obtained from an interview with the caregiver and child, conducted by a research nutritionist. The quantity and the size of each food portion was estimated using standardized containers as described previously [13, 14], and subsequently analyzed using the Indian food composition tables to determine nutrient and caloric intake [15]. Dietary intake of children was compared with the recommended dietary allowance (RDA) and expressed as a percentage of RDA [16].

\section{Laboratory evaluation}

The following routine laboratory tests were done: automated complete blood examination (Sysmex XT-2000i, Sysmex, Kobe, Japan), peripheral smear by manual examination and quantitative buffy coat assay for malarial parasites. CD4 $\mathrm{T}$ cell absolute counts and percentage values were measured using flow cytometry (FACSCalibur, Becton Dickenson Biosciences) and HIV viral load was performed using Real Time PCR (Abbot RealTime HIV-1, Abbott Park, IL, USA). Stool samples were processed into a direct saline and iodine wet mount and examined microscopically to detect intestinal parasites. Serum folate, vitamin $B_{12}$, serum iron, transferrin and ferritin levels were measured by electrochemiluminescence using Roche Cobas 6000 (Roche Diagnostics Pvt. Ltd, Basel, Switzerland). Serum soluble transferrin receptor (sTfR), retinol binding protein levels and highsensitivity C-reactive protein levels were assayed by 
immunonephelometry using BN ProSpec, Siemens Ltd (Siemens, Erlangen, Germany).

\section{Definitions}

Anemia was categorized based on the WHO criteria for definition of anemia and was stratified based on age (children aged 6-59 months, hemoglobin (Hb) concentration $<11.0 \mathrm{~g} / \mathrm{dl} ; 5-11$ years, $\mathrm{Hb}<11.5 \mathrm{~g} / \mathrm{dl} ; \geq 12$ years, $\mathrm{Hb}<12.0 \mathrm{~g} / \mathrm{dl}$ )[17]. Severe anemia was defined as $\mathrm{Hb}$ $<7.0 \mathrm{~g} / \mathrm{dl}$ for children aged $6-59$ months; and $\mathrm{Hb}<8.0$ for those 5 years and older [17]. Iron deficiency was defined as soluble transferrin receptor-log ferritin index (sTfR/ lf) $\geq 1.5$; [18]. Presence of inflammation was indicated by ultrasensitive C-Reactive Protein (CRP) $>1.0 \mathrm{mg} / \mathrm{dl}$. Anemia of inflammation was defined as $\mathrm{sTfR} / \mathrm{lf} \leq 1.5$ plus CRP $>1.0 \mathrm{mg} / \mathrm{dl}$ [18]. Vitamin $\mathrm{B}_{12}$ deficiency was defined as serum $B_{12} \leq 210 \mathrm{pg} / \mathrm{mL}$ [19] and folate deficiency as serum folate $<140 \mathrm{ng} / \mathrm{ml}$ [19]. Vitamin A deficiency was indicated by retinol binding protein (RBP) as $<0.7 \mu$ moles $/ \mathrm{L}$ [20], which is a known sensitive and specific marker for vitamin A deficiency in the context of HIV infection and malnutrition [21].

\section{Follow-up visits and iron therapy}

Children were assessed every 3 months for one year. Clinical and anthropometric measurements were collected every 3 months, while laboratory assessments took place every 6 months. The study did not include any intervention, however clinical guidelines from the World Health Organization were followed by the clinician for iron therapy [22]. For treatment, a colloidal form of iron containing ferric hydroxide with elemental iron of $53 \%$ (Tonoferon, East India Pharmaceutical Works Limited) prescribed at a dose of $3 \mathrm{mg} / \mathrm{kg}$ body weight was used. Iron was dispensed for 3 months, following which iron was continued for 6 months if the children remained anemic.

\section{Statistical analysis}

Frequency distributions of anemia and micronutrient deficiencies were calculated using simple proportions and compared using chi square tests. Bivariate analysis of explanatory variables and anemia prevalence was followed by logistic regression and multivariate analysis of all identified covariates that were statistically significant at a level of $p<0.05$ to describe the final model of predictors of anemia. Chi square tests were used to explore categorical variables, and odds ratios with $95 \%$ confidence intervals expressed the association between the variables. All statistical analysis was performed using Stata v13.0 software. All tests were 2-tailed and were considered statistically significant at a level of $p<0.05$.

\section{Results}

Baseline characteristics

Between February 2011 and August 2012, 286 children were screened at all participating sites. Parents' HIV status was unknown in 7 children, there were 34 children who did not fulfill age criteria and were either below 2 years or older than 12 years, duration of ART was less than 6 months in 2 children during the period of recruiting, and caregivers of 3 children refused to give consent. The final number of children recruited for the study was 240 and were equally distributed among the three sites. Among the 240 children enrolled in the study, mean age was 7.7 years (SD 2.6), and there were 131 males (54.6\%). Distribution of WHO Clinical staging among the children was as follows: stage 1 and 2: $80.8 \%$; stage 3 and 4: $19.2 \%$. Median CD4 percentage was $25 \%$ (IQR $18,33)$, median absolute CD4 count was 773 cells $/ \mathrm{mm}^{3}$ $(\mathrm{IQR}=507,1251)$ and proportion of children with baseline CD $4<350$ cells $/ \mathrm{mm}^{3}$ was $27 / 240$ (11.3\%). There was a high prevalence of malnutrition at baseline; proportion of children with stunting (height for age $\mathrm{Z}$ score $\mathrm{HAZ}<-2$ ) was $40.0 \%$; those underweight (weight for age $\mathrm{Z}$ score $\mathrm{WAZ}<-2$ ) was $45.4 \%$, and those with wasting (weight for height $\mathrm{Z}$ score $\mathrm{WHZ}<-2$ ) was $23.3 \%$, and those children with low BMI (body mass index $\mathrm{Z}$ score BMIZ<-2) was $29.2 \%$. The proportion of children on ART at baseline was 104/240 (43.3\%). ART regimens included zidovudine or stavudine, with lamivudine and nevirapine, efavirenz or lopinavir/ritonavir. The prevalence of intestinal helminthic infestation was 28/240 (11.7\%) in this population, and included Ascaris lumbricoides (11/28), Giardia lamblia (7/28), Enterobius vermicularis (7/28), Trichomonas hominis (2/28) and Entamoeba histolytica (1/28).

\section{Anemia prevalence and associations}

Anemia was prevalent in 113/240 children (47.1 \%), while severe anemia was seen in 16/240 (6.7\%). Overall iron deficiency was prevalent in 154/240 (64.4\%). Vitamin A deficiency prevalence was 43/240 (17.9\%), while folate and vitamin $\mathrm{B}_{12}$ deficiencies were $1 / 240$ (0.4 \%) and $15 / 240(6.3 \%)$ respectively. Risk factors for anemia in a bivariate model included stunting, CD $4<25 \%$, detectable viral load $\geq 400$ copies $/ \mathrm{ml}$ and absence of ART and vitamin A deficiency (Table 1). When all the potential risk factors were added to a multivariate model, we found that significant independent risk factors for anemia were stunted status (OR 1.9, 95\%CI 1.1-3.4), low CD4 count (OR 3.2, 95\%CI 1.8-5.7), detectable viral load (OR 2.4, 95\%CI 1.1-5.4) and vitamin A deficiency (OR 2.5, 95\%CI 1.1-5.6) (Table 1). Drugs such as co-trimoxazole did not have an impact on anemia prevalence. 
Table 1 Bivariate and multivariate analysis of risk factors of anemia in HIV

\begin{tabular}{|c|c|c|c|c|c|c|}
\hline \multirow[t]{2}{*}{ Parameters } & \multirow{2}{*}{$\begin{array}{l}\text { Anemic children } \\
n=113\end{array}$} & \multirow{2}{*}{$\begin{array}{l}\text { Non-anemic children } \\
n=128\end{array}$} & \multicolumn{2}{|c|}{ Bivariate analysis } & \multicolumn{2}{|c|}{ Multivariate analysis } \\
\hline & & & OR $(95 \% \mathrm{Cl})$ & $p$ & OR $(95 \% \mathrm{Cl})$ & $p$ \\
\hline Younger age (<6 years) & $28(24.8)$ & $23(18.1)$ & $1.5(0.8-2.8)$ & 0.209 & - & - \\
\hline Underweight (Weight-for age Z score <-2) & $57(50.4)$ & $51(42.2)$ & $1.5(0.9-2.5)$ & 0.111 & - & - \\
\hline Stunted (Height-for age Z score <-2) & $53(46.9)$ & $42(33.1)$ & $1.8(1.1-3.0)$ & $0.029^{*}$ & $1.9(1.1-3.4)$ & $0.034^{*}$ \\
\hline Not on antiretroviral therapy & $81(71.7)$ & $55(43.3)$ & $3.3(1.9-5.7)$ & $<0.001^{*}$ & $1.4(0.7-3.0)$ & 0.359 \\
\hline Low CD4\% (<25 \%) & $75(66.4)$ & $41(32.3)$ & $4.1(2.4-7.1)$ & $<0.001^{*}$ & $3.2(1.8-5.7)$ & $<0.001^{*}$ \\
\hline Viral load $\geq 400$ (copies/ml) & $92(82.4)$ & $67(52.8)$ & $3.9(2.2-7.1)$ & $<0.001^{*}$ & $2.4(1.1-5.4)$ & $0.035^{*}$ \\
\hline Intestinal helminth infestation & $15(13.2 \%)$ & $13(10.2)$ & $1.1(0.6-3.1)$ & 0.601 & - & - \\
\hline Inflammation (ultrasensitive CRP > 1.0) mg/dl) & $66(58.4)$ & $69(54.8)$ & $1.2(0.7-2.0)$ & 0.570 & - & - \\
\hline $\begin{array}{l}\text { Iron deficiency (soluble transferrin } \\
\text { receptor-log ferritin index (sTfR/lf) } \geq 1.5 \text { ) }\end{array}$ & $74(65.5)$ & $80(62.9)$ & $1.1(0.7-1.9)$ & 0.688 & - & - \\
\hline $\mathrm{B}_{12}$ deficiency (serum $\mathrm{B}_{12} \leq 210 \mathrm{pg} / \mathrm{mL}$ ) & $11(9.8)$ & $4(3.2)$ & $3.3(1.0-10.6)$ & 0.047 & - & - \\
\hline $\begin{array}{l}\text { Vit A deficiency (retinol binding protein (RBP) } \\
<0.7 \mu \text { moles } / L \text { ) }\end{array}$ & $30(26.6)$ & $13(10.2)$ & $3.2(1.6-6.0)$ & $0.001^{*}$ & $2.5(1.1-5.6)$ & $0.022^{*}$ \\
\hline
\end{tabular}

* refers to statistical significance at a level or $p>0.05$

\section{Etiology of anemia}

Among those children with anemia, iron deficiency was the commonest micronutrient deficiency; 74/113 (65.5\%) had iron deficiency anemia, Vitamin A deficiency was seen in 30/113 (26.6 \%), while 1/112 (0.9\%) and 9/112 (8.0\%) had folate and vitamin $B_{12}$ deficient respectively. Anemia of inflammation was seen in 66/113 (58.4\%) of anemic children. There were several overlapping micronutrient deficiencies as well as evidence of inflammation that was associated with anemia (Fig. 1). At the initial testing stage, there were no children whose anemia could be attributed to zidovudine. The presence of ART at baseline did not impact the etiology pattern of anemia.

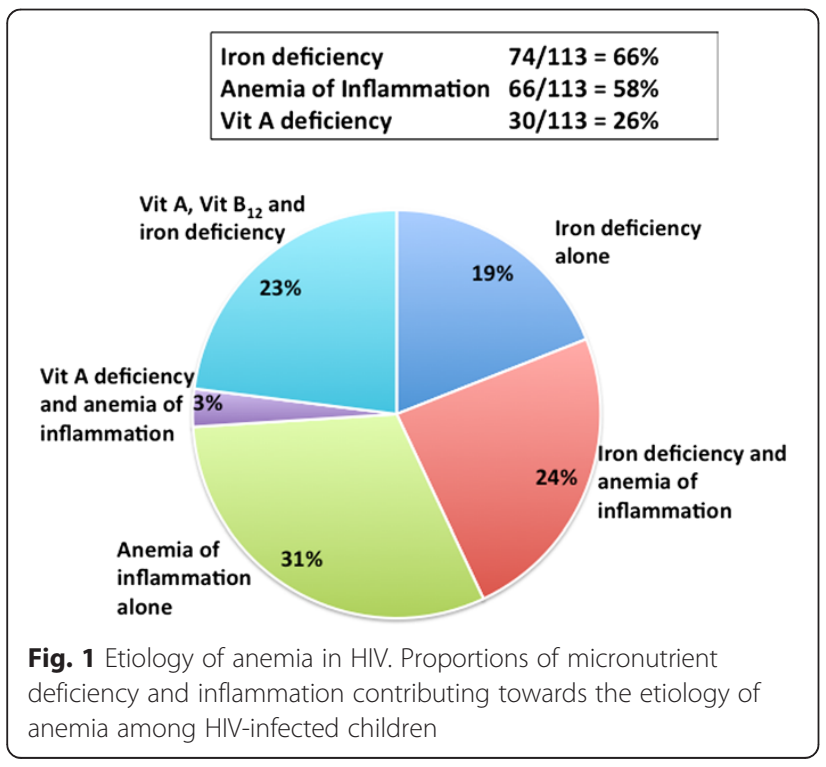

\section{Dietary intake}

Median intake of nutrients expressed as percentage of RDA was $36 \%$ for iron, and $72 \%$ for energy, indicating that on an average, most of the children were obtaining less than half of the recommended dietary allowance for iron. The proportion of children getting less than minimum RDA (at least $75 \%$ RDA) for iron was as high as $79.9 \%$ and for energy was $43.3 \%$ (Table 2). These proportions did not change significantly over the 1-year follow-up period.

\section{Follow-up and iron therapy}

Follow-up data were available for 194/240 (80.8 \%) children who returned for their 6-month and 12 month visit. There were 18 children who were transferred out to a different ART center and could not return for follow-up visits, 8 children died, 1 child whose caregiver withdrew consent, and 19 were lost-to-follow-up. During the follow-up period, ART was initiated among 42 children, and 32 received zidovudine-based treatment. Among these, 3 children developed zidovudine-related bone marrow suppression with severe anemia and were switched to stavudine or abacavir-based ART.

Among 113 children who were initially anemic, 77 children received therapeutic iron after the baseline visit. Of the remaining 35 children who did not receive iron, 25 children had haemoglobin $>11 \mathrm{~g} / \mathrm{dl}$ and were not considered "anemic" and the clinical decision to give iron was not taken. Two children died within 1 month of baseline visit, and the remaining 8 children were amongst those who were lost-to-follow-up as described earlier. Assessment of adherence to iron, assessed by telephone or personal contact during the clinic visit, indicated that $70 \%$ of the children reported $100 \%$ 
Table 2 Dietary intake among children with HIV

\begin{tabular}{|c|c|c|c|c|}
\hline Nutrient & Median intake in our population (IQR) & $\begin{array}{l}\text { Recommended } \\
\text { ICMR, } 2010\end{array}$ & Allowance, & Children obtaining $<75 \%$ of RDA $n(\%)$ \\
\hline \multirow[t]{4}{*}{ Energy (kcal/day) } & $1275(966,1615)$ & $4-6 y r:$ & 1350 & \multirow[t]{4}{*}{$104(43.3)$} \\
\hline & $1362(1011,1695)$ & 7-9 yr: & 1690 & \\
\hline & $1571(1146,1930)$ & Boys $10-12$ yr: & 2190 & \\
\hline & $1487(1024,1720)$ & Girls 10-12 yr: & 2110 & \\
\hline \multirow[t]{4}{*}{ Protein (g/day) } & $37.6(25.9,49.7)$ & $4-6 \mathrm{yr}:$ & 20.1 & \multirow[t]{4}{*}{$104(43.3)$} \\
\hline & $40.0(31.0,53.6)$ & 7-9 yr: & 29.5 & \\
\hline & $47.0(37.6,67.7)$ & Boys $10-12$ yr: & 39.9 & \\
\hline & $41.0(29.5,53.6)$ & Girls 10-12 yr: & 40.4 & \\
\hline \multirow[t]{4}{*}{ Fat (g/day) } & $32.4(22.8,45.8)$ & $4-6 \mathrm{yr}:$ & 25 & \multirow[t]{4}{*}{$49(20.4)$} \\
\hline & $39.1(26.4,52.5)$ & 7-9 yr: & 30 & \\
\hline & $45.4(28.7,56.0)$ & Boys $10-12$ yr: & 35 & \\
\hline & $37.2(28.7,52.9)$ & Girls 10-12 yr: & 35 & \\
\hline \multirow[t]{4}{*}{ Iron (mg/day) } & $7.9(5.1,10.4)$ & $4-6 \mathrm{yr}:$ & 13 & \multirow[t]{4}{*}{$187(77.9)$} \\
\hline & $8.4(5.8,11.9)$ & $7-9 \mathrm{yr}:$ & 16 & \\
\hline & $9.6(6.9,13.0)$ & Boys $10-12$ yr: & 21 & \\
\hline & $9.0(5.9,11.9)$ & Girls 10-12 yr: & 27 & \\
\hline Vitamin A (retinol, mg/day) & $748.6(427.4,1069.3)$ & $1-17$ yr: & 600 & $128(53.3)$ \\
\hline $\mathrm{B}_{12}$ (mg/day) & $1.4(0.8,2.3)$ & $1-17 \mathrm{yr}:$ & $0.2-1.0$ & 47 (19.6) \\
\hline \multirow[t]{3}{*}{ Folate (mg/day) } & \multirow[t]{3}{*}{$148.3(108.8,208.4)$} & $4-6 \mathrm{yr}:$ & 100 & \multirow[t]{3}{*}{$35(14.6)$} \\
\hline & & 7-9 yr: & 120 & \\
\hline & & 10-12 yr: & 140 & \\
\hline
\end{tabular}

The dietary intakes of macro- and micronutrients are presented in relation to standard recommended dietary allowances (RDA) for Indian children. Age and genderstratified values are indicated. The last column refers to the proportion of children in the study who receive less than $75 \%$ of standard RDA for each nutrient studied $I Q R$ interquartile range, ICMR Indian Council of Medical Research

adherence, $20 \%$ missed 1-2 weeks of therapy, and $10 \%$ missed over 2 weeks of iron therapy. Mild adverse effects to iron were reported by 17/77 (22\%), and included dark colored stools, nausea, diarrhea or constipation and mild abdominal discomfort. All these were minor side effects that diminished after 2-3 weeks of first reporting. The number of hospitalizations for intercurrent infections (pneumonia, tuberculosis and other infections) was similar in both groups (3 among iron supplementation group and 2 in the non-iron group). No malaria was reported among these children.

\section{Effect of iron therapy}

Among children who received iron for 3 months, median hemoglobin increased from $10.4 \mathrm{~g} / \mathrm{dl}$ to $10.9 \mathrm{mg} / \mathrm{dl}$ (Table 3). Hemoglobin change was maximum after 1 year, and increased to $11.3 \mathrm{mg} / \mathrm{dl}$ among children who received iron for up to 6 months. Children who were on ART plus iron had a greater hemoglobin increase compared to children who were on ART alone, without iron (Hb change 1.3 versus $0.4 \mathrm{gm} / \mathrm{dl}$ respectively, $p=0.009$ ). The prevalence of iron deficiency also decreased from 68.1 to $49.2 \%(p=0.04)$ among those who received iron.
In addition, this group also showed a decreased trend in clinical severity; severe WHO clinical stage (Stage 3, 4) decreased from $25.7 \%$ at baseline to $10.9 \%$ at 1 year of follow-up. A smaller decrease in clinical severity stage (16.7-12.5 \%) was seen among those who did not receive iron. There was no significant change in the presence of chronic inflammation among those who received iron supplements. Iron did not independently affect growth or CD4 parameters; overall improvement of WAZ and HAZ were seen over one year irrespective of iron supplements.

\section{Discussion}

Our study revealed a significant prevalence of anemia among children with perinatally-acquired HIV, with major determinants being iron deficiency, chronic inflammation and vitamin A deficiency in this population. Anemia was associated with stunting and poor disease control (detectable viral load and low CD4 counts). The use of therapeutic iron appeared to be safe in these children, and resulted in significant improvement in the degree of anemia, iron deficiency and clinical progression in this population. 
Table 3 Change in parameters following iron therapy

\begin{tabular}{|c|c|c|c|c|}
\hline Parameters & Timing (from enrolment) & Received iron supplements & Iron supplement not received & $p$ \\
\hline \multirow[t]{3}{*}{ Hemoglobin (g/dl) } & Baseline & 10.4 & 12.0 & $0.003^{*}$ \\
\hline & 3 months & 10.9 & 12.0 & $0.04^{*}$ \\
\hline & 1 year & 11.3 & 11.9 & 0.2 \\
\hline \multirow[t]{2}{*}{ Weight-for-age Z score } & Baseline & -2.2 & -1.9 & 0.08 \\
\hline & 1 year & -1.9 & -1.8 & 0.2 \\
\hline \multirow[t]{2}{*}{ Height-for-age Z score } & Baseline & -1.6 & -1.5 & 0.2 \\
\hline & 1 year & -1.3 & -1.7 & 0.05 \\
\hline \multirow[t]{2}{*}{ CD4\% } & Baseline & 21.0 & 20.5 & 0.6 \\
\hline & 1 year & 26.5 & 26.0 & 0.7 \\
\hline \multirow{2}{*}{$\begin{array}{l}\text { Prevalence of advanced WHO clinical } \\
\text { stage (Stage } 3,4)(\%)\end{array}$} & Baseline & 25.7 & 16.7 & $0.04^{*}$ \\
\hline & 1 year & 10.9 & 12.5 & 1.0 \\
\hline \multirow[t]{2}{*}{ Fe deficiency prevalence (STfR/If) >1.5) (\%) } & Baseline & 68.1 & 62.7 & $0.04^{*}$ \\
\hline & 1 year & 49.2 & 58.0 & 1.0 \\
\hline \multirow[t]{2}{*}{ Chronic inflammation (CRP > 1) (\%) } & Baseline & 62.9 & 52.4 & 0.05 \\
\hline & 1 year & 57.9 & 40.0 & 0.06 \\
\hline
\end{tabular}

Children $(n=194)$ were followed for one year, and the change in parameters are compared between those who received and did not short-course iron supplementation

WHO World Health Organization, sTfR/If soluble transferrin receptor-log ferritin index, CRP C-reactive protein

* refers to statistical significance at a level or $p>0.05$

Other recent studies have indicated that anemia continues to be a problem in the post-ART era. In many low-income settings, unattended malnutrition, helminthic infections, poor dietary intake and food insecurity may often abrogate the positive effects of ART [23]. Prevalence of anemia and undernutrition in Nigeria in the setting of ART was reported as $70 \%[9]$. The IeDEA West Africa collaboration study involving children from seven countries indicated that although anemia was less common among those on ART, severe malnutrition is linked to severe anemia despite the presence of ART [24]. From the TREAT Asia Pediatric HIV Observational Database, among 1648 children on ART, incidence of new onset anemia was low in the setting of ART, but was associated with malnutrition, advanced disease state and the use of zidovudine-containing regimens [25].

Major nutritional determinants of anemia include micronutrient deficiencies such as iron and vitamin $\mathrm{A}$, folate and $B_{12} \cdot[26,27]$. Few studies in India have scrutinized the role of different micronutrients in the development of anemia, and our results showing the role played by iron deficiency, vitamin A deficiency along with chronic inflammation are useful in determining targeted nutritional strategies for management. Although our study did not indicate any significant association with intestinal parasitic infestation, the triple burdens of HIV, intestinal parasitic infections and anemia often coexist in children, and are often associated with lower CD4+ $\mathrm{T}$ cell levels in HIV infected children [28]. Further, stool examination for ova and cysts is notoriously insensitive and the prevalence of soil-transmitted helminth infestation was probably under-estimated. Other studies of Indian children have shown prevalence ranging from 13 to $68 \%$ [29] with lower prevalence reported from urban areas.

The alliance between HIV infection and iron deficiency is incompletely characterized. Several studies indicated that children infected with HIV have iron deficiency less frequently than children without HIV infection [30-32], and a review on iron status in children with HIV indicated that the prevalence of iron deficiency is low in both high and low-income areas [33]. However, the chronic inflammatory state frequently present during HIV infection may lead to underestimation of iron deficiency in this population, because markers of iron status such as ferritin are elevated in chronic inflammation $[34,35]$. On the other hand, inflammation-induced hypoferraemia may result in functional iron deficiency, which renders iron unavailable for erythropoiesis. The resulting anemia also makes iron unavailable for infective organisms that require iron for growth and proliferation, and results in anemia of inflammation [18].

Persistent anemia in the setting of ART can be a reflection of underlying pro-inflammatory pathways induced by HIV [36]. A study in a large cohort of adults and children in Uganda and Zimbabwe showed that while ART significantly reduced the prevalence of anemia two years after initiating therapy, $13 \%$ of the population continued to be anemic, attributable to the chronic inflammatory state [37]. The role of chronic inflammation in causing anemia has been highlighted in several studies 
of HIV-infected individuals. Among 299 Thai and Cambodian children with HIV, although anemia was prevalent among $50 \%$ of the children, iron deficiency prevalence, as measured by ferritin levels was less than $3 \%$ overall; and most of the anemia was attributed to anemia of inflammation and thalassemia trait [38]. Since sTfR is a biomarker that is less influenced by inflammatory parameters, we leveraged this property to obtain a more accurate appraisal of iron deficiency in our population. This may explain the high prevalence of iron deficiency identified in this setting. There is little doubt that nutritional anemia, including iron deficiency anemia is a major co-morbidity in children with HIV. Iron deficiency is also strongly associated with impaired neurobehavioral development [39] and needs to be addressed in this population. In malariaendemic places, this equipoise is often disrupted, and iron deficiency appears to be protective against clinical malaria in children [40], with iron supplementation being associated with an increased risk of malaria and hospitalization or death [11].

Our results indicate that therapeutic iron taken for a period of 3-6 months appear safe with only minor transient adverse effects, and with no increase in incidence of malaria or hospitalization. These results may not be generalizable to a malaria-endemic setting where the risks of iron supplementation have been consistently noted. The use of therapeutic iron in our study population also showed a beneficial effect on growth and disease progression. In a placebo-controlled randomized controlled trial in Malawi, researchers showed that iron supplementation in anemic HIV-infected children had beneficial effects on hemoglobin, anemia prevalence and CD4 counts at 6 months but increased the risk of malaria [41]. This trial also noted that among iron-deficient children, iron theapy was associated with a reduced risk of progression to AIDS. Importantly, our study indicated that a combination of iron and ART worked well to improve hemoglobin, rather than ART alone [42].

Dietary sources of iron among these south Indian children were inadequate. An appalling $80 \%$ of the children in this study received less iron than the minimum RDA for age (defined as $<75 \%$ RDA). A prospective study from South Africa indicated insufficient dietary iron among children; although anemia improved over the 18-month time period with supplementation, iron deficiency paradoxically increased from $15 \%$ at baseline to $37 \%$ during the same period, suggesting that low dose iron supplementation along with dietary increase would be a useful strategy [43]. In low-income settings, low dietary iron intake and poor bioavailability of dietary iron may be a challenge. Some inexpensive strategies to counter this can include use of unrefined sugar and local unpolished cereals, measures to improve the bioavailability of iron such as soaking cereals and legumes, and combining cereals and legumes with food sources of vitamin $\mathrm{C}$, such as fresh fruit and vegetables [44].

Our study may be limited by the relatively small sample size, and the lack of a randomized controlled intervention to assess the effect of iron therapy. In addition, the use of ferritin as a marker can result in non-representative values for iron deficiency in the setting of chronic inflammation; however we have used, along with ferritin, sTfR for defining iron deficiency, which reflects the degree of tissue iron supply as well as iron stores [45]. We did not assess the presence of hemoglobinopathies in this setting, and hence this data is unknown. Previous studies have found the prevalence of alpha and beta-thalassemia to be low in this geographic area [46]; hence the non-inclusion of this parameter in our assessment was unlikely to have influenced anemia prevalence or etiology.

\section{Conclusions}

Our study highlights the finding that Indian children with HIV have significant presence of anemia that is orchestrated by iron deficiency, although vitamin A deficiency and chronic inflammation also play a role. Dietary sources of iron remain highly inadequate. The use of standard WHO-recommended therapeutic iron particularly for durations of up to 6 months appears to be safe in this setting, and is associated with beneficial effects on anemia, iron deficiency and HIV disease progression. Further clinical and cost-effectiveness studies of iron therapy will be useful in streamlining policy decisions on anemia management among HIV-infected children in non-malaria endemic regions.

\section{Abbreviations}

HIV: Human Immunodeficiency Virus; ART: Anti-Retroviral Therapy; WHO: World Health Organization; RDA: Recommended Dietary Allowance; $\mathrm{Hb}$ : Hemoglobin; sTfR/lf: soluble transferrin receptor-log ferritin index; CRP: CReactive Protein; RBP: Retinol Binding Protein; OR: Odds Ratio; WAZ: Weightfor-Age Z Score; HAZ: Height-for-Age Z Score; IQR: Interquartile range; ICMR: Indian Council of Medical Research.

\section{Competing interests}

The authors declare that they have no competing interests.

\section{Author' contributions}

AS conceived of the study, obtained funding, coordinated the study sites, supervised overall data collection and analyses, and drafted the manuscript. SS and NK participated in the design of the study and supervised data collection at the Chennai sites. KK performed data management and statistical analyses. BPK and SE participated in data collection and analyses. All authors read and approved the final manuscript.

\section{Acknowledgements}

The authors would like to thank the ART Officer and staff at the ART Centre, St. John's Medical College Hospital, as well as the staff at the ART Center, Kilpauk Medical College, Chennai and the HIV clinic at YRGCare for their excellent teamwork and patient care. We are grateful to the National AIDS Control Organisation (NACO), Government of India, for providing support for these subjects, and for facilitating the conduct of this study. Most importantly, we are ever grateful to the study subjects and their caregivers for participating in this study. We acknowledge the financial support of Indian Council of Medical Research for conducting this study (Reference no 
5/7/253/BGL/07-RHN). We also acknowledge partial support from the Wellcome Trust/DBT India Alliance Senior Fellowship grant awarded to AS (Reference No IA/S/13/2/501017).

\section{Author details}

'Department of Pediatrics, St. John's Medical College Hospital, Sarjapur Road, Bangalore 560034, India. '2Department of Public Health Sciences, Karolinska Institutet, Stockholm, Sweden. ${ }^{3}$ Department of Clinical Research, National Institute for Research in Tuberculosis, 1 Sathiyamoorthy Road, Chetput, Chennai, India. ${ }^{4}$ YRG Center for AIDS Research and Education, Voluntary Health Services Taramani, Chennai, India. ${ }^{5}$ Antiretroviral Treatment Center,

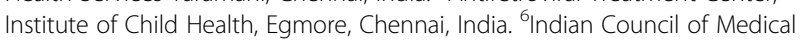
Research (ICMR), New Delhi, India.

\section{Received: 4 June 2015 Accepted: 9 October 2015} Published online: 19 October 2015

\section{References}

1. Clark TD, Mmiro F, Ndugwa C, Perry RT, Jackson JB, Melikian G, et al. Risk factors and cumulative incidence of anaemia among human immunodeficiency virus-infected children in Uganda. Ann Trop Paediatr. 2002;22(1):11-7.

2. Eley BS, Sive AA, Shuttleworth M, Hussey GD. A prospective, cross-sectional study of anaemia and peripheral iron status in antiretroviral naive, HIV-1 infected children in Cape Town, South Africa. BMC Infect Dis. 2002;2:3.

3. Chatterjee A, Bosch RJ, Kupka R, Hunter DJ, Msamanga Gl, Fawzi WW. Predictors and consequences of anaemia among antiretroviral-naive HIV-infected and HIV-uninfected children in Tanzania. Public Health Nutr. 2010;13(2):289-96.

4. Mwiru RS, Spiegelman D, Duggan C, Seage 3rd GR, Semu H, Chalamilla G, et al. Nutritional Status and Other Baseline Predictors of Mortality among HIVInfected Children Initiating Antiretroviral Therapy in Tanzania. J Int Assoc Prov AIDS Care. 2015;14(2):172-9.

5. Calis JC, van Hensbroek MB, de Haan RJ, Moons P, Brabin BJ, Bates I. HIVassociated anemia in children: a systematic review from a global perspective. AIDS. 2008;22(10):1099-112.

6. Rajasekaran S, Jeyaseelan L, Ravichandran N, Gomathi C, Thara F, Chandrasekar C. Efficacy of antiretroviral therapy program in children in India: prognostic factors and survival analysis. J Trop Pediatr. 2009;55(4):225-32.

7. Shah SR, Tullu MS, Kamat JR. Clinical profile of pediatric HIV infection from India. Arch Med Res. 2005;36(1):24-31.

8. Shet A, Mehta S, Rajagopalan N, Dinakar C, Ramesh E, Samuel NM, et al. Anemia and growth failure among HIV-infected children in India: a retrospective analysis. BMC Pediatr. 2009:9:37.

9. Anyabolu HC, Adejuyigbe EA, Adeodu OO. Undernutrition and anaemia among HAART-naive HIV infected children in Ile-lfe, Nigeria: a case-controlled, hospital based study. Pan Afr Med J. 2014;18:77.

10. Adetifa I, Okomo U. Iron supplementation for reducing morbidity and mortality in children with HIV. Cochrane Database Syst Rev. 2009;1:CD006736.

11. Sazawal S, Black RE, Ramsan M, Chwaya HM, Stoltzfus RJ, Dutta A, et al. Effects of routine prophylactic supplementation with iron and folic acid on admission to hospital and mortality in preschool children in a high malaria transmission setting: community-based, randomised, placebo-controlled trial. Lancet. 2006;367(9505):133-43.

12. The WHO. Child Growth Standards, World Health Organization. 2007 Available at http://www.who.int/childgrowth/en/. Accessed 2 May 2015.

13. Bharathi AV, Kurpad AV, Thomas T, Yusuf S, Saraswathi G, Vaz M Development of food frequency questionnaires and a nutrient database for the Prospective Urban and Rural Epidemiological (PURE) pilot study in South India: methodological issues. Asia Pac J Clin Nutr. 2008;17(1):178-85.

14. Shet A, Arumugam K, Rajagopalan N, Dinakar C, Krishnamurthy S, Mehta S, et al. The prevalence and etiology of anemia among HIV-infected children in India. Eur J Pediatr. 2012;171(3):531-40.

15. Gopalan C, Rama Sastri BV, Balasubramanian SC, Narasinga Rao BS, Deosthale YG, Pant KC. Nutritive value of Indian foods. Hyderabad: National Institute of Nutrition (ICMR); 1989

16. National Institute of Nutrition: Nutrient requirements \& recommended dietary allowances for Indians, Indian Council of Medical Research. Available at http://icmr.nic.in/final/RDA-2010.pdf. Accessed 2 May 2015.

17. World Health Organization. Hemoglobin concentrations for the diagnosis of anemia and assessment of severity, Vitamin and Mineral Nutrition
Information System. Geneva: World Health Organization. Available at http:// www.who.int/vmnis/indicators/haemoglobin/en/. Accessed 2 May 2015.

18. Weiss G, Goodnough LT. Anemia of chronic disease. N Engl J Med. 2005;352(10):1011-23.

19. Pfeiffer CM, Johnson CL, Jain RB, Yetley EA, Picciano MF, Rader Jl, et al. Trends in blood folate and vitamin B-12 concentrations in the United States, 1988 2004. Am J Clin Nutr. 2007:86(3):718-27.

20. de Pee S, Dary O. Biochemical indicators of vitamin A deficiency: serum retinol and serum retinol binding protein. J Nutr. 2002;132(9 Suppl):2895S-901.

21. Baeten JM, Richardson BA, Bankson DD, Wener MH, Kreiss JK, Lavreys L, et al. Use of serum retinol-binding protein for prediction of vitamin $A$ deficiency: effects of HIV-1 infection, protein malnutrition, and the acute phase response. Am J Clin Nutr. 2004;79(2):218-25.

22. World Health Organization. Iron deficiency anaemia: assessment, prevention and control. A guide for programme managers. Geneva: World Health Organization; 2001. Available at http://www.who.int/nutrition/publications/ micronutrients/anaemia_iron_deficiency/WHO_NHD_01.3/en/. Accessed on 21 January 2015

23. Nyesigire Ruhinda E, Bajunirwe F, Kiwanuka J. Anaemia in HIV-infected children: severity, types and effect on response to HAART. BMC Pediatr. 2012;12:170.

24. Renner LA, Dicko F, Koueta F, Malateste K, Gueye RD, Aka E, et al. Anaemia and zidovudine-containing antiretroviral therapy in paediatric antiretroviral programmes in the leDEA Paediatric West African Database to evaluate AIDS. J Int AIDS Soc. 2013;16:18024.

25. Bunupuradah T, Kariminia A, Chan KC, Ramautarsing R, Huy BV, Han N, et al. Incidence and predictors of severe anemia in Asian HIV-infected children using first-line antiretroviral therapy. Int J Infect Dis. 2013;17(10):e806-10.

26. Castaldo A, Tarallo L, Palomba E, Albano F, Russo S, Zuin G, et al. Iron deficiency and intestinal malabsorption in HIV disease. J Pediatr Gastroenterol Nutr. 1996;22(4):359-63.

27. Eley BS, Sive AA, Abelse L, Kossew G, Cooper M, Hussey GD. Growth and micronutrient disturbances in stable, HIV-infected children in Cape Town. Ann Trop Paediatr. 2002;22(1):19-23.

28. Mengist HM, Taye B, Tsegaye A. Intestinal Parasitosis in Relation to CD4 + T Cells Levels and Anemia among HAART Initiated and HAART Naive Pediatric HIV Patients in a Model ART Center in Addis Ababa, Ethiopia. PLoS One. 2015;10(2):e0117715.

29. Greenland K, Dixon R, Khan SA, Gunawardena K, Kihara JH, Smith JL, et al. The epidemiology of soil-transmitted helminths in bihar state, India. PLoS Negl Trop Dis. 2015;9(5):e0003790

30. Meira DG, Lorand-Metze I, Toro AD, Silva MT, Vilela MM. Bone marrow features in children with HIV infection and peripheral blood cytopenias. J Trop Pediatr. 2005:51(2):114-9.

31. Ray A, Ndugwa C, Mmirot F, Ricks MO, Semba RD. Soluble transferrin receptor as an indicator of iron deficiency in HIV-infected infants. Ann Trop Paediatr. 2007;27(1):11-6.

32. Calis JC, Phiri KS, Faragher EB, Brabin BJ, Bates I, Cuevas LE, et al. Severe anemia in Malawian children. N Engl J Med. 2008;358(9):888-99.

33. Esan MO, Jonker FA, Hensbroek MB, Calis JC, Phiri KS. Iron deficiency in children with HIV-associated anaemia: a systematic review and meta-analysis. Trans R Soc Trop Med Hyg. 2012;106(10):579-87.

34. Kreuzer KA, Rockstroh JK. Pathogenesis and pathophysiology of anemia in HIV infection. Ann Hematol. 1997;75(5-6):179-87.

35. Lewis DK, Whitty CJ, Epino H, Letsky EA, Mukiibi JM, van den Broek NR. Interpreting tests for iron deficiency among adults in a high HIV prevalence African setting: routine tests may lead to misdiagnosis. Trans R Soc Trop Med Hyg. 2007;101(6):613-7.

36. Redig AJ, Berliner N. Pathogenesis and clinical implications of HIV-related anemia in 2013. Hematol Am Soc Hematol Educ Program. 2013;2013:377-81.

37. Jaganath D, Walker AS, Ssali F, Musiime V, Kiweewa F, Kityo C, et al. HIV-associated anemia after 96 weeks on therapy: determinants across age ranges in Uganda and Zimbabwe. AIDS Res Hum Retroviruses. 2014;30(6):523-30.

38. Kosalaraksa P, Bunupuradah T, Vonthanak S, Wiangnon S, Hansudewechakul R, Vibol $U$, et al. Prevalence of anemia and underlying iron status in naive antiretroviral therapy HIV-infected children with moderate immune suppression. AIDS Res Hum Retroviruses. 2012;28(12):1679-86.

39. Lozoff B, Georgieff MK. Iron deficiency and brain development. Semin Pediatr Neurol. 2006;13(3):158-65. 
40. Gwamaka M, Kurtis JD, Sorensen BE, Holte S, Morrison R, Mutabingwa TK, et al. Iron deficiency protects against severe Plasmodium falciparum malaria and death in young children. Clin Infect Dis. 2012;54(8):1137-44.

41. Esan MO, van Hensbroek MB, Nkhoma E, Musicha C, White SA, Ter Kuile FO, et al. Iron supplementation in HIV-infected Malawian children with anemia: a double-blind, randomized, controlled trial. Clin Infect Dis. 2013;57(11):1626-34.

42. Kibaru EG, Nduati R, Wamalwa D, Kariuki N. Impact of highly active antiretroviral therapy on hematological indices among HIV-1 infected children at Kenyatta National Hospital-Kenya: retrospective study. AIDS Res Ther. 2015;12:26.

43. Kruger HS, Balk LJ, Viljoen M, Meyers TM. Positive association between dietary iron intake and iron status in HIV-infected children in Johannesburg, South Africa. Nutr Res (New York, NY). 2013;33(1):50-8.

44. Gibson RS, Bailey KB, Gibbs M, Ferguson EL. A review of phytate, iron, zinc, and calcium concentrations in plant-based complementary foods used in low-income countries and implications for bioavailability. Food Nutr Bull. 2010;31(2 Suppl):S134-46.

45. Punnonen $\mathrm{K}$, Irjala K, Rajamaki A. Serum transferrin receptor and its ratio to serum ferritin in the diagnosis of iron deficiency. Blood. 1997;89(3):1052-7.

46. Pasricha SR, Black J, Muthayya S, Shet A, Bhat V, Nagaraj S, et al.

Determinants of anemia among young children in rural India. Pediatrics. 2010;126(1):e140-9.

\section{Submit your next manuscript to BioMed Central and take full advantage of:}

- Convenient online submission

- Thorough peer review

- No space constraints or color figure charges

- Immediate publication on acceptance

- Inclusion in PubMed, CAS, Scopus and Google Scholar

- Research which is freely available for redistribution 